\title{
Developmental Changes in Dendritic Spine Morphology in the Striatum and Their Alteration in an A53T $\alpha$-Synuclein Transgenic Mouse Model of Parkinson's Disease
}

\author{
Laxmi Kumar Parajuli, ${ }^{1}$ Ken Wako, ${ }^{1}$ Suiki Maruo, ${ }^{1}$ Soichiro Kakuta, ${ }^{2,3}$ Tomoyuki Taguchi, ${ }^{4}$ \\ (-)Masashi Ikuno, ${ }^{4}$ Hodaka Yamakado, ${ }^{4}$ Ryosuke Takahashi, ${ }^{4}$ and ${ }^{\circledR}$ Masato Koike ${ }^{1,5}$
}

https://doi.org/10.1523/ENEURO.0072-20.2020

${ }^{1}$ Department of Cell Biology and Neuroscience, Juntendo University Graduate School of Medicine, Tokyo 113-8421, Japan, ${ }^{2}$ Department of Cellular and Molecular Neuropathology, Juntendo University Graduate School of Medicine, Tokyo 113-8421, Japan, ${ }^{3}$ Laboratory of Morphology and Image Analysis, Research Support Center, Juntendo University Graduate School of Medicine, Tokyo 113-8421, Japan, ${ }^{4}$ Department of Neurology, Kyoto University Graduate School of Medicine, Kyoto 606-8507, Japan, and ${ }^{5}$ Advanced Research Institute for Health Science, Juntendo University, Tokyo 113-8421, Japan

\begin{abstract}
The aging process is accompanied by various neurophysiological changes, and the severity of neurodegenerative disorders such as Parkinson's disease (PD) increases with aging. However, the precise neuroanatomical changes that accompany the aging process in both normal and pathologic conditions remain unknown. This is in part because there is a lack of high-resolution imaging tool that has the capacity to image a desired volume of neurons in a high-throughput and automated manner. In the present study, focused ion beam/scanning electron microscopy (FIB/SEM) was used to image striatal neuropil in both wild-type (WT) mice and an A53T bacterial artificial chromosome (BAC) human $\alpha$-synuclein (A53T-BAC-SNCA) transgenic (Tg) mouse model of PD, at 1, 3, 6, and 22 months of age. We demonstrated that spine density gradually decreases, and average spine head volume gradually increases with age in WT mice, suggesting a homeostatic balance between spine head volume and spine density. However, this inverse relationship between spine head volume and spine density was not observed in A53T-BAC-SNCA Tg mice. Taken together, our data suggest that PD is accompanied by an abnormality in the mechanisms that control synapse growth and maturity.
\end{abstract}

Key words: $\alpha$-synuclein; A53T; dendrite; dendritic spines; FIB/SEM; Parkinson's disease

\section{Significance Statement}

Currently, the clinical diagnosis of Parkinson's disease (PD) is based on the presence of motor symptoms. However, these symptoms only manifest after a significant proportion of dopaminergic cells have degenerated. The latent, prodromal phase is therefore of particular interest for the development of disease-modifying therapies to slow down or reverse the course of neurodegeneration. Although clinical markers to diagnose patients in the prodromal phase are gradually emerging, a structural marker that defines this phase has not yet been identified. Structural changes likely occur in the synapse before the onset of neurodegeneration. Thus, this study performed an ultrastructural analysis of synapses in a mouse model of prodromal PD and revealed distinct, age-dependent structural changes.

Received February 27, 2020; accepted August 12, 2020; First published August 17, 2020.

The authors declare no competing financial interests.
Author contributions: L.K.P. and M.K. designed research; L.K.P., K.W., S.M., S.K., T.T., and M.I. performed research; L.K.P. analyzed data; L.K.P. and M.K. wrote the paper; H.Y. and R.T. contributed unpublished reagents/analytic tools. 


\section{Introduction}

Parkinson's disease (PD) is a progressive neurodegenerative disorder characterized by motor dysfunctions including rigidity, akinesia, tremor, and bradykinesia (Jankovic, 2008; Erro and Stamelou, 2017; Simon et al., 2020). Its pathologic hallmarks include the aggregation of $\alpha$-synuclein in cellular inclusions, resulting in the formation of Lewy bodies, and the progressive loss of nigrostriatal dopaminergic neurons and consequent basal ganglia dysfunction (Polymeropoulos et al., 1997; Spillantini et al., 1998; Riederer et al., 2019; Tsukita et al., 2019). Currently, there is no effective cure for PD, and this is partly because of our lack of understanding about the precise synapticlevel changes that are associated with this disease. In particular, it remains unknown whether synaptic abnormalities precede the appearance of different behavioral phenotypes associated with PD. This knowledge may eventually aid in the early diagnosis of the disease.

Medium spiny neurons (MSNs), the principal neurons in the striatum, have dendrites that possess thorn-shaped dendritic spines. Because the vast majority of excitatory synaptic inputs impinge on these structures (Wilson et al., 1983; Gerfen, 1988), there has been a surge of interest in examining morphologic abnormalities of dendritic spines in various neurologic diseases (Penzes et al., 2011; Kuwajima et al., 2013). Most of our current knowledge about the alterations that occur in synaptic morphology in $P D$ is derived from neurotoxin-induced rodent and primate models. Both 1-methyl-4-phenyl-1,2,3,6-tetrahydropyridine (MPTP) and 6-hydroxydopamine (6-OHDA), the commonly used neurotoxins for the generation of PD animal models, cause a marked decrease in the number of spines and an alteration in spine head volume in striatal dendrites (Solis et al., 2007; Villalba et al., 2009; Garcia et al., 2010; Naskar et al., 2013; Villalba and Smith, 2013, 2018; Funamizu et al., 2017; Gagnon et al., 2017). The structural abnormalities observed in neurotoxin-induced animal models are unlikely to be an artifact of drug application because postmortem analyses of PD patients' brains have also revealed a severe loss of dendritic spines in this disease (McNeill et al., 1988; Stephens et al., 2005; Zaja-Milatovic et al., 2005).

This work was supported by the Ministry of Education, Culture, Sports, Science, and Technology Grant-in-Aid for Scientific Research [A] JP18H04041 (to R.T.), Grant-in-Aid for Scientific Research [C] JP20K07743 (to M.K.), Grantin-Aid for Early-Career Scientists 18K14842 (to L.K.P.), and Private School Branding Project (M.K.); the Integrated Neurotechnologies for Disease Studies (Brain/MINDS) from Japan Agency for Medical Research and Development (AMED) Grants JP18dm0207020 and JP19dm0207070 (to R.T.) and JP18dm0207024 (M.K.), the Japan Science and Technology Agency, CREST, Grant JP17gm0710011 (to R.T.), and the Mitsubishi Foundation Grant 29125 (to R.T.).

Acknowledgements: We thank Dr. Hiroyuki Hioki, Dr. Yu-shin Sou, Dr. Mutsumi Yokota, Dr. Kenta Yamauchi, and the members of the Takahashi and Koike laboratories for their input throughout the course of the project.

Correspondence should be addressed to Masato Koike at mkoike@ juntendo.ac.jp.

https://doi.org/10.1523/ENEURO.0072-20.2020

Copyright (C) 2020 Parajuli et al.

This is an open-access article distributed under the terms of the Creative Commons Attribution 4.0 International license, which permits unrestricted use, distribution and reproduction in any medium provided that the original work is properly attributed.
Although neurotoxin-induced animal models nicely recapitulate the PD etiology observed in humans, the complete degeneration of dopaminergic cells in the substantia nigra pars compacta (SNc) after neurotoxin application suggests that these animal models mimic severe or latestage PD. Similarly, postmortem analysis in humans usually represents the end stage of PD. Although informative, knowledge of structural changes in the final phase of PD are of limited use in the presymptomatic detection and early treatment of this disease. In addition, the knowledge obtained from neurotoxin-induced animal models may not necessarily represent a generalizable feature of PD. Importantly, the etiology of PD cannot be pinpointed to a single cause (Klein and Westenberger, 2012). Moreover, structural analysis of a genetically perturbed mouse model, the Irrk2-G2019S knock-in mouse, has revealed the presence of dendritic spines with a larger head volume than in the WT mouse but no change in spine density (Matikainen-Ankney et al., 2016). These results strongly indicate that structural changes observed in genetically perturbed animal models are distinct from those generated by pharmacological means.

Several studies have linked the $\alpha$-synuclein gene, $S N C A$, to autosomal dominant PD, and at least six different point mutations (A30P, A53E, A53T, E46K, G51D, and $\mathrm{H} 50 \mathrm{Q}$ ) in SNCA have been identified in familial PD to date (Polymeropoulos et al., 1997; Krüger et al., 1998; Zarranz et al., 2004; Gasser, 2009; Lees et al., 2009; AppelCresswell et al., 2013; Kiely et al., 2013; Pasanen et al., 2014). A study has recently reported the generation of a novel A53T SNCA bacterial artificial chromosome (BAC) transgenic ( $\mathrm{Tg}$ ) mouse that demonstrates prodromal symptoms of PD such as hyposmia and rapid eye movement sleep behavior disorders, without any obvious motor dysfunction (Taguchi et al., 2020a). This mouse is therefore an excellent resource for studying structural changes in the early stages of PD. Here, we use focused ion beam/scanning electron microscopy (FIB/SEM) to study age-related structural changes in the A53T-BACSNCA Tg mouse model. Our results demonstrate that spine density decreases and spine head volume increases with age in wild-type (WT) mice, suggesting a homeostatic balance between spine density and spine head volume. However, in the A53T-BAC-SNCA Tg mouse, spine density was slightly higher than in the WT mouse of corresponding age, and the relative frequency of thintype, presumably immature spines was also higher. Furthermore, the head volume of dendritic spines remained similar throughout the different developmental stages in A53T-BAC-SNCA Tg mice. Our results suggest that, in prodromal PD, distinct age-dependent synaptic structural changes occur.

\section{Materials and Methods}

\section{Animals}

Animal care and handling were performed in accordance with the animal welfare and experimental guidelines of the authors' institutions. All experimental protocols were approved by the animal care and use committee of 
the authors' institutions. The methodological details for the generation and genotyping of A53T-BAC-SNCA Tg mice are described in a previous study (Taguchi et al., 2020a). As in the previous study, heterozygous mice (hereafter referred to as A53T-BAC-SNCA mice) were used. For the present study, 16 male mice (eight mice for FIB/SEM analysis and eight mice for pre-embedding immunogold labeling) were used. For each experiment, one C57BL/6 WT mouse and one A53T-BAC-SNCA mouse were used at 1, 3, 6, and 22 months of age.

\section{Anesthesia, fixation, and sectioning}

Mice were deeply anesthetized by inhalation of sevoflurane before being transcardially perfused with $20 \mathrm{ml}$ of Ringer's solution supplemented with $0.1 \%$ heparin. After the initial flushing out of blood from the vascular system, mice for FIB/SEM analysis were perfused with $100 \mathrm{ml}$ of $2 \%$ paraformaldehyde (PFA) and $2 \%$ glutaraldehyde (GA) in $0.1 \mathrm{M}$ cacodylate buffer. For pre-embedding immunogold labeling, $\sim 70 \mathrm{ml}$ of fixative containing $4 \%$ PFA and $0.1 \%$ GA in $0.1 \mathrm{M}$ phosphate buffer (PB; pH 7.4) was used. The perfusion speed was kept at $5-6 \mathrm{ml}$ of fixative/min both for the FIB/SEM analysis and pre-embedding immunogold labeling. Each brain was extracted from the skull; for FIB/SEM analysis, brains were postfixed at $4^{\circ} \mathrm{C}$ overnight in the same fixative solution, while brains for preembedding immunogold labeling were subjected to $1 \mathrm{~h}$ of postfixation at RT in 4\% PFA in $0.1 \mathrm{~m}$ PB. Following the thorough washing of brains in PBS, they were sectioned at $1 \mathrm{~mm}$ using a tissue chopper for FIB/SEM analysis and at $60 \mu \mathrm{m}$ using a Linear Slicer Pro7 vibratome (Dosaka EM) for pre-embedding immunogold labeling.

\section{Tissue preparation for FIB/SEM}

Brain blocks were rinsed several times in $0.1 \mathrm{~m}$ cacodylate buffer containing $2 \mathrm{mM} \mathrm{CaCl}_{2}$, and then incubated for $1 \mathrm{~h}$ in ferrocyanide-reduced osmium solution containing $1.5 \%$ potassium ferrocyanide and $2 \%$ aqueous osmium tetroxide $\left(\mathrm{OsO}_{4}\right)$ in $0.1 \mathrm{~m}$ cacodylate buffer. Blocks were thoroughly rinsed in distilled water before being incubated for $2 \mathrm{~h}$ in $1 \%$ tannic acid solution. The sections were then incubated in $2 \% \mathrm{OsO}_{4}$ for $30 \mathrm{~min}$ and in $1 \%$ aqueous uranyl acetate solution overnight. Following several washes with distilled water, brain blocks were dehydrated in $50 \%$, $70 \%, 80 \%, 90 \%$, and $100 \%$ ethanol for $10 \mathrm{~min}$ each. Blocks were then embedded in epoxy resin Epok812 (Okenshoji) and cured for $48 \mathrm{~h}$ at $60^{\circ} \mathrm{C}$.

\section{FIB/SEM imaging}

The striatal tissue surface was exposed using a Leica Ultracut UCT ultramicrotome. The block was then placed in a metal stub and sputter coated with gold-palladium to prevent specimen charging E1010 (E1010; Hitachi). Serial FIB/SEM images at $40-50 \mathrm{~nm}$ increments were acquired from the dorsolateral striatum on a Helios Nanolab 660 FIB/SEM using Auto Slice \& View G3 software (FEI) to automate the serial milling and imaging process. The surface of the brain block was milled by the thermal energy produced by $0.77 \mathrm{nA}$ of gallium $(\mathrm{Ga})$ ion beam current that was accelerated at a voltage of $30 \mathrm{kV}$. The electron beam had a dwell time of $5 \mu \mathrm{s}$. The acceleration voltage in the backscattered electron detector was set to $2.0 \mathrm{kV}$ with $0.8 \mathrm{nA}$. Images were obtained at $15,000 \times$ magnification covering a distance of $13.82 \mu \mathrm{m}$ in the horizontal direction and $11.69 \mu \mathrm{m}$ in vertical direction at a resolution of $4.5 \mathrm{~nm} /$ pixel. The lateral resolution $(x, y)$ and axial resolution ( $z$, section thickness) used in our study is within the typical range used for electron microscopic (EM) imaging of neuronal structures. At this resolution, we can clearly resolve synaptic vesicles, postsynaptic density (PSD), small spines and thin axons.

\section{Three-dimensional (3D) reconstruction and morphologic quantification of spines and dendrites}

3D reconstruction and analysis of spine and dendrite morphology was performed in accordance with Sato and Okabe (2019). Briefly, FIB/SEM images were first automatically aligned using Fiji software (Schindelin et al., 2012). Image stacks were then loaded onto Reconstruct software (Fiala, 2005) and dendritic shafts and spines were manually segmented. The numerical values for the surface area and the volume of dendritic spines were obtained from the Reconstruct software. PSD area was obtained by multiplying the section thickness with the summed length of PSD in consecutive sections. Spine neck length and dendritic length were obtained in 3D-reconstructed images in reference to a square of $1 \mu \mathrm{m}$ in length on each side. Spine density was obtained by dividing the total number of spines in a dendrite by the dendritic length.

\section{Pre-embedding immunogold labeling}

Sections from the dorsolateral striatum of WT and A53T-BAC-SNCA mice were rinsed briefly in $25 \mathrm{~mm}$ PBS (25 mm PB and $150 \mathrm{~mm} \mathrm{NaCl}$ ) and then incubated in a cryoprotectant solution containing $25 \%$ sucrose and $10 \%$ glycerol in $0.1 \mathrm{~m}$ PB. Sections were then permeabilized by repeated cycles of freezing in liquid nitrogen and thawing. Thereafter, the sections were washed three times for $20 \mathrm{~min}$ in $50 \mathrm{~mm}$ Tris-buffered saline (TBS; $50 \mathrm{~mm}$ Tris$\mathrm{HCl}, \mathrm{pH} 7.4$, and $150 \mathrm{~mm} \mathrm{NaCl}$ ) and incubated in a blocking solution containing $10 \%$ normal goat serum (NGS) in TBS for $1 \mathrm{~h}$. The sections were then incubated for $48 \mathrm{~h}$ in rabbit monoclonal anti-phosphorylated $\alpha$-synuclein antibody (phospho-S129, clone EP1536Y, catalog number ab51253; Abcam) at a dilution of 1:1000 in 2\% NGS in TBS. The sensitivity and specificity of this antibody was confirmed in a previous study (Delic et al., 2018). Sections were then washed three times for $20 \mathrm{~min}$ each with TBS and incubated overnight at $4^{\circ} \mathrm{C}$ in $1.4 \mathrm{~nm}$ nanogold-conjugated goat anti-rabbit secondary antibody (Nanoprobes). The sections were washed in TBS and fixed with 1\% GA in PBS for 10 min. Following several washes in PBS, sections were briefly rinsed in distilled water, and immunogold signals were then enhanced using an $\mathrm{HQ}$ silver enhancement kit (Nanoprobes). The sections were postfixed in $1 \% \mathrm{OsO}_{4}$ for $40 \mathrm{~min}$, incubated with uranyl acetate for $35 \mathrm{~min}$, dehydrated in a graded series of ethanol, 
subjected to two changes of propylene oxide, and then immersed in Durcupan resin (ACM Fluka, Sigma-Aldrich) overnight. Sections were then flat-embedded between glass slides and cured for $48 \mathrm{~h}$ at $60^{\circ} \mathrm{C}$. Ultrathin sections $(70 \mathrm{~nm})$ were cut with a Leica Ultracut UCT ultramicrotome. Ultrathin sections were stained for 1 min with $1 \%$ lead citrate and observed with a Hitachi HT7700 transmission electron microscope (TEM).

\section{Statistics}

Statistical analysis was performed using IBM SPSS statistics software (IBM, version 24). The normality of the datasets was assessed using the Shapiro-Wilk test. Statistical differences between two datasets were examined using a Student's $t$ test or Mann-Whitney $U$ test, depending on the outcome of the normality analysis. To examine statistical differences between three or more groups, we used one-way ANOVA for parametric datasets and the Kruskal-Wallis test for non-parametric datasets. The distribution of spine head volume among various ages was analyzed by Kolmogorov-Smirnov $Z$ test. Statistical correlation between two datasets was examined using the Spearman's rank order test. Unless otherwise mentioned, data are expressed as mean \pm SEM.

\section{Results}

\section{Reconstruction of striatal dendrites and spines from FIB/SEM}

Our sample preparation and imaging protocol produced FIB/SEM images with high structural integrity, and the membrane contours of dendrites, spines, and presynaptic axons were clearly visible. Synaptic contacts and PSDs of excitatory synapses were also clearly discernible (Fig. $1 A$ ). Using $\sim 250-400$ serial FIB/SEM images (number of sections imaged for WT at 1 month $=374,3$ months $=360$, 6 months $=333$, 22 months $=396$; number of sections imaged for A53T-BAC-SNCA at 1 month $=253,3$ months $=$ 295,6 months $=382,22$ months $=380$ ), we could reconstruct approximately a 5 - to $25-\mu \mathrm{m}$ length of dendrites, including all the spines protruding from that dendritic segment. We analyzed 65 dendrites and 1285 spines in this study. We reconstructed seven dendrites and 132 spines from a 1-month-old WT mouse, seven dendrites and 148 spines from a 1-month-old A53T-BAC-SNCA mouse, eight dendrites and 177 spines from a 3-monthold WT mouse, eight dendrites and 251 spines from a 3month-old A53T-BAC-SNCA mouse, seven dendrites and 109 spines from a 6-month-old WT mouse, seven dendrites and 151 spines from a 6-month-old A53T-BACSNCA mouse, 11 dendrites and 156 spines from a 22month-old WT mouse, and 10 dendrites and 161 spines from a 22-month-old A53T-BAC-SNCA mouse. The average length (in $\mu \mathrm{m}$ ) of reconstructed dendrites was $9.2 \pm 0.61$ (median $=8.6$, range $=8.0-12.5$ ) in a 1-monthold WT mouse, $8.7 \pm 0.75$ (median $=8.7$, range $=5.4-10.9)$ in a 1-month-old A53T-BAC-SNCA mouse, $12.4 \pm 0.52$ (median $=13.2$, range $=9.8-13.9)$ in a 3 -month-old WT mouse, $13.8 \pm 1.20($ median $=13.3$, range $=9.7-19.5)$ in a 3-month-old A53T-BAC-SNCA mouse, $11.8 \pm 0.85$ (median =
10.5, range $=9.4-14.5)$ in a 6-month-old WT mouse, $11.0 \pm 0.72$ (median $=11.4$, range $=7.8-12.9$ ) in a 6month-old A53T-BAC-SNCA mouse, $13.4 \pm 0.83$ (median = 13.7, range $=8.6-17.6$ ) in a 22-month-old WT mouse, and $11.7 \pm 1.49$ (median $=11.0$, range $=7.2-24.1$ ) in a 22-monthold A53T-BAC-SNCA mouse.

Each dendrite contained spines with varying dimensions of head volume and neck length. Figure $1 B-/$ shows representative dendrites reconstructed from each mouse. Qualitative inspection of the 3D-reconstructed dendritic segments gave the impression that, in WT mice, spine abundance in dendrites decreases with age, while head volume of spines increases with age (Fig. 1B-E). Numerous small spines were predominant in the 1-month-old mouse, while large spines outnumbered small spines in the 6- and 22-month-old WT mice. Similar to the trend observed in WT mice, an agerelated decline in dendritic spine abundance was also observed in the mutant mice. However, an increase in spine head volume with age was not obvious in A53T-BAC-SNCA mice (Fig. 1F-l).

\section{Alterations in dendritic spine ultrastructure in A53T- BAC-SNCA mice}

To precisely understand the structural abnormalities in A53T-BAC-SNCA mice, we performed an extensive analysis of serial FIB/SEM images to obtain quantitative data for various parameters that can influence synaptic changes. In a dendrite, the density of spines, the volume of spine heads, and the length of spine necks all critically influence the strength of synaptic transmission (Tønnesen and Nägerl, 2016; Parajuli et al., 2017). Thus, we quantified and compared these parameters for each age and genotype. In WT mice, the mean spine densities (expressed as the number of spines $/ \mu \mathrm{m}$ length of dendrite) in dendrites were $2.0 \pm 0.14$ (median $=1.9$, range $=1.6-2.6$, $n=132$ spines, seven dendrites), $1.8 \pm 0.17$ (median $=1.9$, range $=1.4-2.9, n=177$ spines, eight dendrites), $1.3 \pm$ 0.14 (median $=1.3$, range $=0.7-2.0, n=109$ spines, seven dendrites), and $1.1 \pm 0.06$ (median $=1.0$, range $=0.8-1.4$, $n=156$ spines, 11 dendrites) at $1,3,6$, and 22 months of age, respectively (Fig. 2A). Spine densities at 6 and 22 months of age were significantly lower than at 1 and 3 months of age ( $p$ values between 1 and 6 months, $p=0.003 ; 1$ and 22 months, $p<0.001 ; 3$ and 6 months, $p=0.03$; 3 and 22 months, $p=0.001$; one-way ANOVA). In contrast, there was no significant difference in spine density between 1 and 3 months of age $(p=1.00$; one-way ANOVA) or 6 - and 22-month-old mice ( $p=1.00$; one-way ANOVA). Spine densities in A53T-BAC-SNCA mice also trended downward with age (Fig. 2A). Mean dendritic spine densities were $2.5 \pm 0.22$ (median $=2.4$, range $=$ 1.7-3.5, $n=148$ spines, seven dendrites), $2.4 \pm 0.21$ (median $=2.5$, range $=1.3-3.0, n=251$ spines, eight dendrites), $2.0 \pm 0.14$ (median $=2.0$, range $=1.5-2.5, n=151$ spines, seven dendrites), and $1.4 \pm 0.21$ (median $=1.2$, range $=0.6-3.1, n=161$ spines, 10 dendrites) at $1,3,6$, and 22 months of age, respectively. In the A53T-BACSNCA mouse, spine densities in striatal dendrites at 1 and 3 months of age were significantly lower than at 22 months of age $(p$ values between 1 and 22 months, 


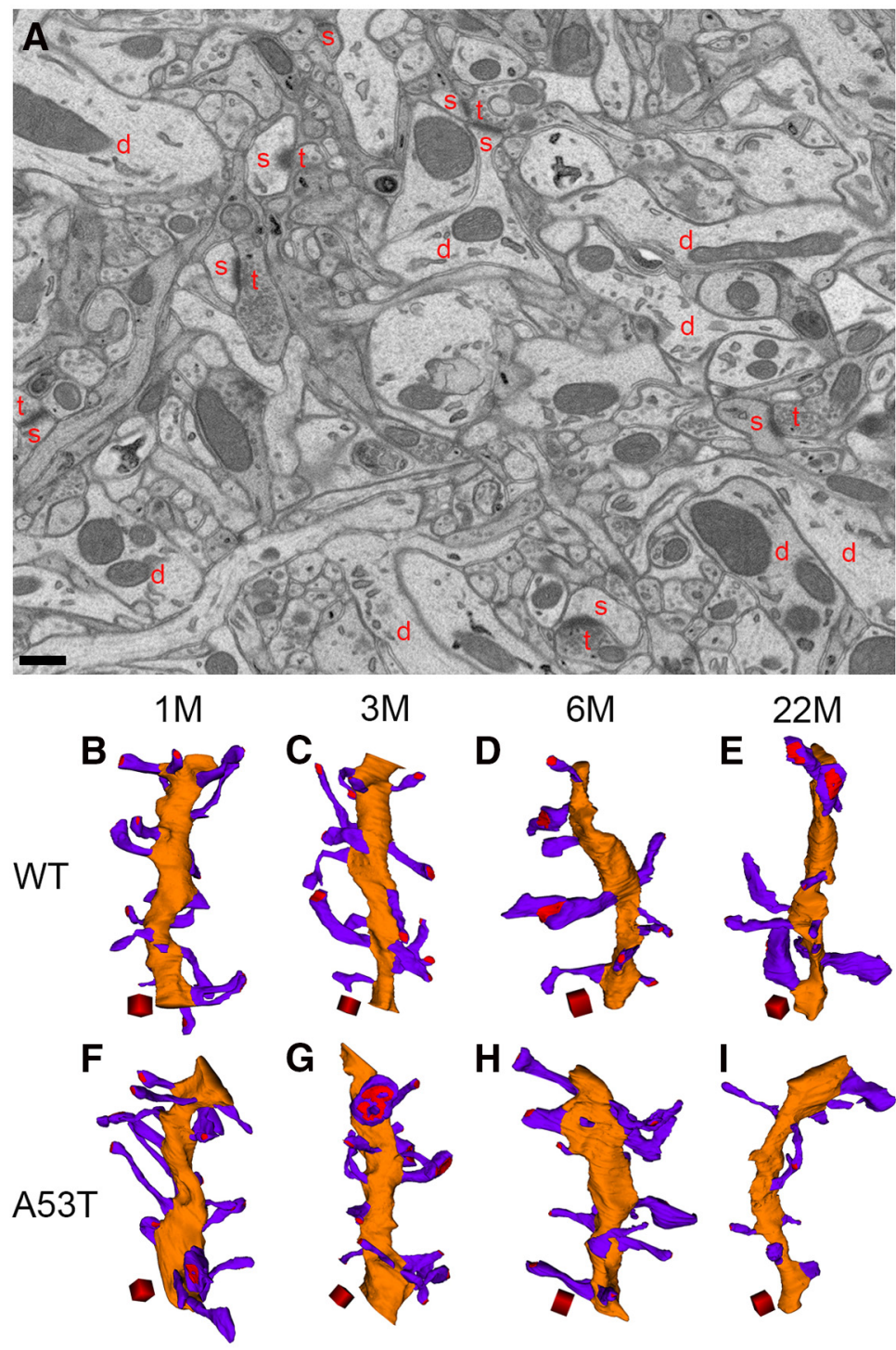

Figure 1. 3D reconstruction of dendrites and spines from WT and A53T-BAC-SNCA mice at different ages. $\boldsymbol{A}$, Membrane contours of dendrites (d), spines (s), and presynaptic terminals ( $t$ ) can be clearly observed in the FIB/SEM image from a 1-month-old WT mouse. Mitochondria and other organelles are also clearly visible. Scale bar: $500 \mathrm{~nm}$. B-I, 3D reconstruction of dendrites (orange) and spines (violet) from WT mice at $1(\boldsymbol{B}), 3(\boldsymbol{C}), 6(\boldsymbol{D})$, and $22(\boldsymbol{E})$ months of age and from A53T-BAC-SNCA mice at $1(\boldsymbol{F}), 3(\boldsymbol{G}), 6$ $(\boldsymbol{H})$, and $22(\boldsymbol{I})$ months of age. Red regions in the spine heads indicate postsynaptic densities. Scale cubes: $0.5 \mu \mathrm{m}$ on each side.

$p=0.01 ; 3$ and 22 months, $p=0.01$; Kruskal-Wallis test). There were no significant differences in spine density in the A53T-BAC-SNCA mice between 1 and 3 months of age ( $p=1.00$; Kruskal-Wallis test), 1 and 6 months of age $(p=1.00$; Kruskal-Wallis test), 3 and 6 months of age $(p=1.00$; Kruskal-Wallis test) and 6 and 22 months of age ( $p=0.48$; Kruskal-Wallis test). A comparison between WT and A53T-BAC-SNCA mice of corresponding ages revealed a significant difference in spine density at 6 months of age ( $p$ value between WT and A53T-BAC-SNCA mice, $p=0.006$; Student's $t$ test). However, there were no significant differences between mice at 1 month of age ( $p$ value between WT and A53T-BAC-SNCA mice, $p=0.11$; Student's $t$ test), at 3 months of age ( $p$ value between WT and A53T-BAC-SNCA mice, $p=0.07$; Student's $t$ test), and at 22 months of age ( $p$ value between WT and A53T-
BAC-SNCA mice $=0.17$; Mann-Whitney $U$ test). These data suggest that, in the A53T-BAC-SNCA mouse, the mechanisms that regulate either spinogenesis or the maintenance of dendritic spines at 6 months of age are impaired.

In contrast to the trend of decreasing spine density with age, there was an increase in average spine head volume with age in WT mice (Fig. 2B). The average spine head volumes (in $\mu \mathrm{m}^{3}$ ) in WT mice were $0.050 \pm 0.0065$ ( median $=0.027$, range $=0.001-0.539, n=132$ spines), $0.074 \pm 0.0071$ (median $=0.041$, range $=0.006-0.688$, $n=177$ spines), $0.084 \pm 0.0110$ (median $=0.045$, range $=$ $0.006-0.778, n=109$ spines), and $0.143 \pm 0.0169$ (median $=$ 0.047 , range $=0.005-1.151, n=156$ spines) at $1,3,6$, and 22 months of age, respectively. The spine head volumes were significantly larger at 3,6 , and 22 months of age than at 
A

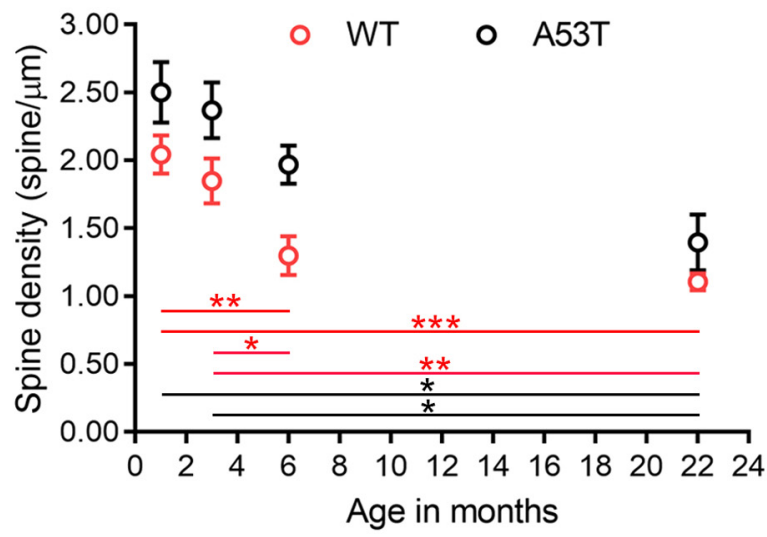

B

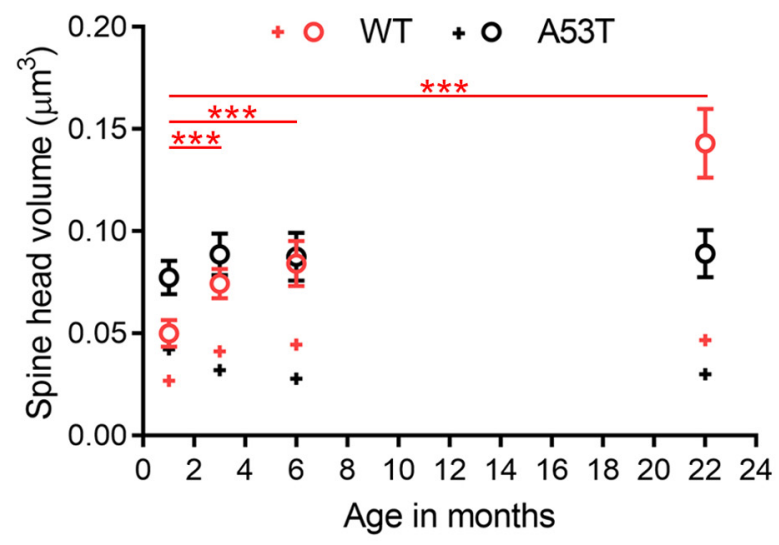

C

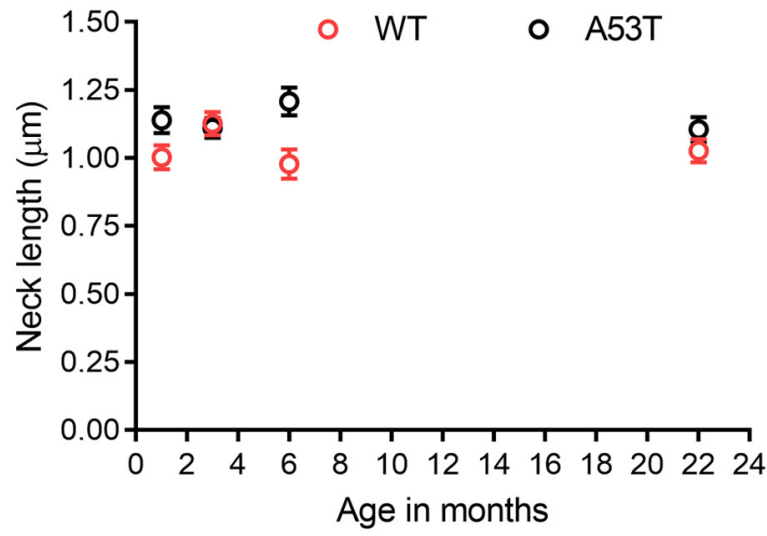

Figure 2. Morphologic alterations in spines in WT and A53TBAC-SNCA mice with age. A, Age-related changes in spine density. The graph shows that spine density decreased with age in both the WT and A53T-BAC-SNCA mice. In WT mice, the spine density at 1 and 3 months was significantly lower compared with that at 6 and 22 months $(* * p=0.003$ between 1 and 6 months, $* * * p<0.001$ between 1 and 22 months, $* p=0.03$ between 3 and 6 months, $* * p=0.001$ between 3 and 22 months; one-way ANOVA). In A53T-BAC-SNCA mice, there were fewer spines at 22 months compared with that at 1 and 3 months $(* p=0.01$ between 1 and 22 months, $* p=0.01$ between 3 and 22 months; Kruskal-Wallis test). $\boldsymbol{B}$, Age-related changes in spine head volume. The average spine head volume increases with age in the WT (red open circle), but not A53T-BAC-SNCA (black open circle), mice. In WT mice, spine head volume at 1 month was significantly smaller than that at 3,6, and 22 months
1 month of age ( $p$ values between 1 and 3 months, $p<0.001 ; 1$ and 6 months, $p<0.001 ; 1$ and 22 months, $p<0.001$; Kruskal-Wallis test). The median head volume of dendritic spines in the striatum remained similar among 3,6 , and 22 months of age, and there was no statistically significant difference in spine head volume among these three ages $(p$ values between 3 and 6 months, $p=1.00 ; 3$ and 22 months, $p=1.00 ; 6$ and 22 months, $p=1.00$; Kruskal-Wallis test). In contrast to what was observed in the WT mice, the average spine head volume in the A53T mutant remained relatively similar across the different ages. The average spine head volumes (in $\mu \mathrm{m}^{3}$ ) in the A53T-BAC-SNCA mice were $0.077 \pm 0.0082$ (median $=0.042$, range $=0.005-0.547$, $n=148$ spines), $0.089 \pm 0.0102$ (median $=0.032$, range $=$ $0.005-1.286, n=251$ spines), $0.088 \pm 0.0116$ (median $=$ 0.028 , range $=0.005-0.782, n=151$ spines), and $0.089 \pm$ 0.0115 (median $=0.030$, range $=0.003-1.138, \quad n=161$ spines) at 1, 3, 6, and 22 months of age, respectively. Spine head volumes were not significantly different among these four different ages ( $p$ values between 1 and 3 months, $p=0.07 ; 1$ and 6 months, $p=0.06 ; 1$ and 22 months, $p=0.11 ; 3$ and 6 months, $p=1.00 ; 3$ and 22 months, $p=1.00$; 6 and 22 months, $p=1.00$; KruskalWallis test). A comparison between WT and A53T-BACSNCA mice of corresponding ages revealed that there was a significant difference in spine head volume at each age $(p$ values between WT and A53T-BAC-SNCA at 1 month, $p<0.001$; at 3 months, $p=0.008$; at 6 months, $p=0.04$; at 22 months, $p=0.006$; Mann-Whitney $U$ test). These data suggest that factors that regulate spine head volume is impaired throughout different developmental stages in A53T-BAC-SNCA mice.

Spine neck is also an important parameter governing the magnitude of synaptic transmission across synaptic contacts. In particular, the dimension of spine neck length governs the degree of attenuation in membrane potential when it travels from the spine head toward its parent dendrite (Araya et al., 2006). Thus, we obtained the average, median, and range of spine neck lengths across different ages both in the WT and A53T-BAC-SNCA mice. The average spine neck length (in $\mu \mathrm{m}$ ) in WT mice were $1.00 \pm 0.045$ (median $=0.96$, range $=0.09-2.30, n=132$ spines), $1.13 \pm 0.043$ (median $=1.10$, range $=0.09-3.18$, $n=176$ spines), $0.98 \pm 0.054$ (median $=0.92$, range $=0.09$ $2.71, n=108$ spines), and $1.03 \pm 0.043$ (median $=0.95$, range $=0.08-2.90, n=156$ spines) at $1,3,6$, and 22 months of age, respectively (Fig. 2C). Spine neck lengths were not significantly different across developmental stages in WT mice $(p$ values between 1 and 3 months, $p=0.48$; 1 and 6 months, $p=1.00 ; 1$ and 22 months, $p=1.00 ; 3$ and

\section{continued}

$(* * * p<0.001$ between 1 and 3 months, $* * * p<0.001$ between 1 and 6 months, ***p $<0.001$ between 1 and 22 months; KruskalWallis test). Median head volume is shown by the + symbol. $\boldsymbol{C}$, Age-related changes in spine neck length. The spine neck length did not vary significantly with age in either WT or A53T-BACSNCA mice. Different levels of significance are denoted by the number of asterisks $(* p<0.05, * * p<0.01$, $* * * p<0.001)$. 
6 months, $p=0.07 ; 3$ and 22 months, $p=0.46$; and 6 and 22 months, $p=1.00$; Kruskal-Wallis test). The average spine neck length in A53T-BAC-SNCA mice was also relatively similar across different ages. The average spine neck lengths (in $\mu \mathrm{m}$ ) in A53T-BAC-SNCA mice were $1.14 \pm 0.047$ (median $=1.07$, range $=0.07-3.16, n=148$ spines), $1.11 \pm 0.036$ (median $=1.03$, range $=0.17-3.30$, $n=249$ spines), $1.21 \pm 0.052$ (median $=1.14$, range $=$ $0.05-3.10, n=149$ spines), and $1.11 \pm 0.045$ (median $=$ 1.09 , range $=0.10-2.64, n=159$ spines) at $1,3,6$, and 22 months of age, respectively. Spine neck lengths were not significantly different among these four different ages ( $p$ values between 1 and 3 months, $p=1.00 ; 1$ and 6 months, $p=1.00 ; 1$ and 22 months, $p=1.00$; 3 and 6 months, $p=1.00$; 3 and 22 months, $p=1.00$; and 6 and 22 months, $p=1.00$; Kruskal-Wallis test). When the spine neck length was compared between WT and A53T-BACSNCA mice of corresponding ages, there was a significant difference at 6 months of age only ( $p$ values between WT and A53T-BAC-SNCA mice at 1 month, $p=0.06$; at 3 months, $p=0.71$; at 6 months, $p=0.002$; at 22 months, $p=0.15$; Mann-Whitney $U$ test). Together, these results demonstrate that each developmental stage is accompanied by distinct changes in spine morphology. Although spine head volume was altered in A53T-BAC-SNCA mice at all examined ages, spine neck length and spine density were only higher in A53T-BACSNCA mice at 6 months of age.

\section{Presence of large dendritic spines in aged WT but not A53T-BAC-SNCA mice}

Despite the large apparent difference in mean spine head volume in WT mice between 6 and 22 months of age, there was no statistically significant difference between these two ages because of similarities in the median spine head volume. Theoretically, although median values are similar, mean spine head volume may be much larger in one group if it contains a number of particularly large spines. To explore this issue, we therefore assessed the relative frequency of small and large spines by broadly categorizing spines into two groups based on their spine head volume. A cutoff volume of $0.04 \mu \mathrm{m}^{3}$ was chosen to group the spines into either large or small types. As the median head volume in adult WT mice ( 3 and 6 months of age) was $\sim 0.04 \mu \mathrm{m}^{3}$, we decided to choose this value as the cutoff to group spines into small and large types. This criterion will split spines into approximately two equal halves with $50 \%$ of the spines whose head volume is below the median head volume as small spines and $50 \%$ of the spines whose head volume is above the median head volume as large spines. Based on these criteria, we observed that in WT mice, relative frequency of small spines was $72.7 \%$ at 1 month of age ( $n=96$ out of 132 ), $48.6 \%$ at 3 months of age ( $n=86$ out of 177 ), $45.0 \%$ at 6 months of age ( $n=49$ out of 109), and $44.2 \%$ at 22 months of age ( $n=69$ out of 156). The relative frequency of small spines at 1 month was higher than that at 3,6 , and 22 months of age. Conversely, the relative frequencies of large spines at 3, 6, and 22 months of age were higher than at 1 month. Relative frequency of large spines was $27.3 \%$ at 1 month of age ( $n=36$ out of 132 ), $51.4 \%$ at 3 months of age ( $n=91$ out of 177$), 55.0 \%$ at 6 months of age ( $n=60$ out of 109), and $55.8 \%$ at 22 months of age ( $n=87$ out of 156). The relative frequencies of small and large spines in WT mice remained fairly similar among 3, 6, and 22 months of age, suggesting that the relative abundance of large and small spines in WT mice considerably changes between 1 and 3 months of age.

The relative frequencies of small and large spines in A53T-BAC-SNCA mice were different from those in WT mice. In A53T-BAC-SNCA mice, higher frequencies of small spines (and a corresponding lower frequency of large spines) were observed at 3, 6, and 22 months of age than at 1 month. At 1, 3, 6, and 22 months of age, respectively, small spines made up $47.3 \%$ (70 out of 148 ), $57.8 \%$ (145 out of 251 ), $60.9 \%$ (92 out of 151 ), and $57.8 \%$ (93 out of 161) of total spines. Our data therefore show a higher frequency of mature spines in WT mice than in A53TBAC-SNCA mice at 3, 6, and 22 months of age.

When all the spine population was taken into consideration, the spine head volume in WT mice at 3, 6, and 22 months were not statistically significant (Fig. $2 B$ ). Next, we wanted to examine if the head volume of either small or large spines differs with age. The mean head volume (in $\mu \mathrm{m}^{3}$ ) of small spines was $0.025 \pm 0.0010$ (median $=0.026$, range $=0.006$ $0.040, n=86$ spines), $0.021 \pm 0.0013$ (median $=0.023$, range $=0.006-0.040, n=49$ spines), and $0.020 \pm 0.0013$ (median $=0.019$, range $=0.005-0.040, n=69$ spines) at 3,6 , and 22 months of age, respectively. The spine head volume of small spines was significantly larger at 3 months of age than at 22 months of age ( $p$ value between 3 and 22 months, $p=0.009$; Kruskal-Wallis test). No statistical significance was detected in the spine head volume of small spines between 3 and 6 months or 6 and 22 months ( $p$ values between 3 and 6 months, $p=0.10 ; 6$ and 22 months, $p=1.00$; Kruskal-Wallis test). The mean head volume (in $\mu \mathrm{m}^{3}$ ) of large spines was $0.121 \pm 0.0120$ (median $=0.073$, range $=0.041-$ $0.688, n=91$ spines), $0.135 \pm 0.0175$ (median $=0.094$, range $=0.040-0.778, n=60$ spines), and $0.241 \pm 0.0259$ (median $=0.130$, range $=0.040-1.151, n=87$ spines) at 3,6 , and 22 months of age, respectively. The spine head volume of large spines was significantly larger at 22 months of age than at 3 and 6 months of age $(p$ values between 3 and 22 months, $p=0.001$; 6 and 22 months, $p=0.04$; KruskalWallis test). In contrast, neither the head volume of small spines nor the large spines showed statistical significance among 3, 6, and 22 months of ages in A53T-BAC-SNCA mice. The mean head volume (in $\mu \mathrm{m}^{3}$ ) of small spines in A53T-BAC-SNCA was $0.020 \pm 0.0007$ (median $=0.018$, range $=0.005-0.040, \quad n=145$ spines), $\quad 0.020 \pm 0.0009$ (median $=0.019$, range $=0.005-0.038, n=92$ spines), and $0.019 \pm 0.0010 \quad$ (median $=0.019$, range $=0.003-0.039$, $n=93$ spines) at 3,6 , and 22 months of age, respectively ( $p$ values between 3 and 6 months, $p=1.00 ; 3$ and 22 months, $p=0.82 ; 6$ and 22 months, $p=1.00$; Kruskal-Wallis test). The mean head volume (in $\mu \mathrm{m}^{3}$ ) of large spines in A53T-BAC-SNCA was $0.182 \pm 0.0211$ (median $=0.094$, range $=0.040-1.286, \quad n=106$ spines), $0.194 \pm 0.0239$ (median $=0.112$, range $=0.041-0.782, n=59$ spines), and 

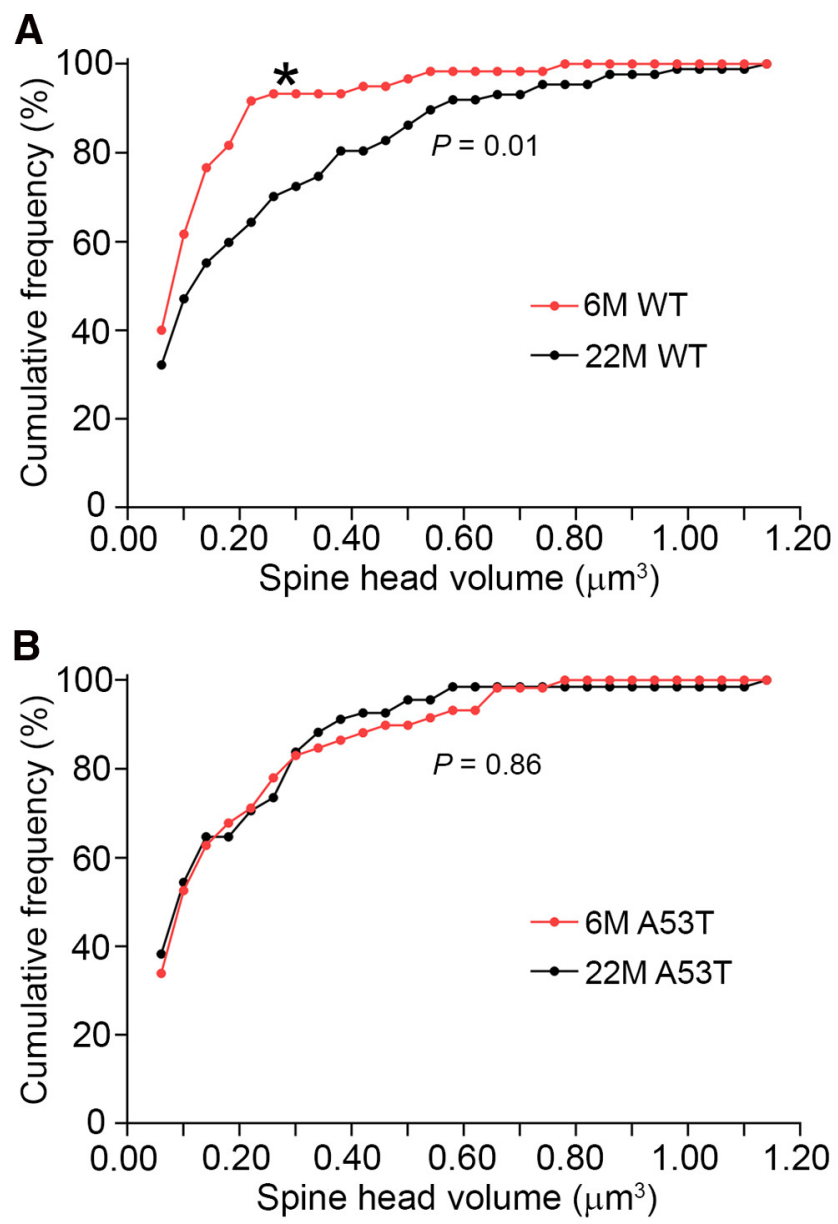

Figure 3. The frequency of large spines increased with age in WT, but not A53T-BAC-SNCA, mice. $\boldsymbol{A}$, The distribution of large spines in WT mice was significantly different between 6 and 22 months of age ( $* p=0.01$, Kolmogorov-Smirnov test). $\boldsymbol{B}$, In contrast, the distribution of large spines was not significantly different between 6 and 22 months of age in A53T-BAC-SNCA mice ( $p=0.86$, Kolmogorov-Smirnov test).

$0.185 \pm 0.0225 \quad($ median $=0.094$, range $=0.040-1.138$, $n=68$ spines) at 3,6 , and 22 months of age, respectively ( $p$ values between 3 and 6 months, $p=0.47$; 3 and 22 months, $p=0.70 ; 6$ and 22 months, $p=1.00$; Kruskal-Wallis test).

In order to compare the distribution of spine head volume of mushroom-type spines between 6 and 22 months of ages in WT mice, we binned the head volume of mushroom-type spines into a bin-width of $0.04 \mu \mathrm{m}^{3}$ and plotted the relative frequency of spines in each bin (Fig. $3 A$ ). The distribution of spine head volume in the 22-month-old mouse showed a rightward shift in comparison to that of the 6-month-old mouse ( $p=0.01$, Kolmogorov-Smirnov $Z$ test). In contrast, spine head volume of the large spines was not statistically different between the 6- and 22-month-old A53T-BAC-SNCA mice ( $p=0.86$, Kolmogorov-Smirnov $Z$ test; Fig. $3 B$ ). These data further reiterate that aging is accompanied by an increase in the frequency of large spines in WT mice.

We also compared the neck length between large and small spines at 3, 6, and 22 months of age. The neck length (in $\mu \mathrm{m}$ ) of small spines in WT was $1.31 \pm 0.061$
( median $=1.26$, range $=0.20-3.14, n=85$ spines), $1.00 \pm$ 0.082 (median $=0.97$, range $=0.09-2.71, n=48$ spines), $1.20 \pm 0.072$ (median $=1.09$, range $=0.16-2.90, \quad n=69$ spines) at 3, 6, and 22 months of age, respectively. The neck length (in $\mu \mathrm{m}$ ) of large spines in WT was $0.95 \pm 0.054 \quad$ (median $=0.91$, range $=0.09-3.18, \quad n=91$ spines), $0.96 \pm 0.073$ (median $=0.87$, range $=0.18-2.69$, $n=60$ spines), and $0.89 \pm 0.048$ (median $=0.77$, range $=$ $0.08-1.89, n=87$ spines) at 3, 6 , and 22 months of age, respectively. The neck length of large spines was significantly shorter than that of small spines at 3 and 22 months of age in WT ( $p$ values between neck lengths of small and large spines at 3 months, $p<0.001 ; 6$ months, $p=0.61 ; 22$ months, $p=0.001$; Mann-Whitney $U$ test). The neck length (in $\mu \mathrm{m}$ ) of small spines in A53T-BAC-SNCA was $1.14 \pm 0.048 \quad$ (median $=1.08$, range $=0.18-2.58$, $n=143$ spines), $1.26 \pm 0.069$ (median $=1.21$, range $=0.05-$ 3.10, $n=90$ spines), and $1.12 \pm 0.063$ (median $=1.09$, range $=0.10-2.64, n=92$ spines) at 3,6 , and 22 months of age, respectively. The neck length (in $\mu \mathrm{m}$ ) of large spines in A53T-BAC-SNCA was $1.06 \pm 0.055$ (median $=1.01$, range $=0.17-3.30, n=106$ spines), $1.13 \pm 0.076$ (median $=$ 1.05 , range $=0.26-2.48, n=59$ spines), and $1.08 \pm 0.063$ (median $=1.12$, range $=0.14-2.22, n=67$ spines) at 3,6 , and 22 months of age, respectively. In contrast to that observed in WT, no statistical significance was detected in the neck lengths between small and large spines at any of the ages in A53T-BAC-SNCA ( $p$ values between neck lengths of small and large spines at 3 months, $p=0.22 ; 6$ months, $p=0.19$; 22 months, $p=0.81$; Mann-Whitney $U$ test). Our data show that A53T-BAC-SNCA mice show deficits in normal spine developmental processes and maturation.

\section{Higher frequency of perforated spines in WT mice at 22 months}

The PSDs of spines are broadly classified into macular and perforated types based on either the absence or presence of discontinuity in the PSD. While PSDs in thin-type spines are known to be predominantly macular, a subset of large or mushroom-type spines possess perforated PSDs (Geinisman et al., 1986). In our serial FIB/SEM images, we occasionally encountered spines with PSDs that showed discontinuity (Fig. $4 A-D$ ). In the 3D reconstructions, some of the perforated PSDs were doughnut-shaped with a hole in the center (Fig. 4E-G). Quantification revealed that the percentages of perforated spines in the WT mice were $1.52 \%, 4.52 \%, 6.42 \%$, and $21.15 \%$ at $1,3,6$, and 22 months, respectively. The percentage of perforated spines at 22 months was 3.29 -fold higher than at 6 months, 4.68-fold higher than at 3 months, and 13.91-fold higher than at 1 month. In the A53T-BAC-SNCA mice, the percentages of perforated spines were $2.70 \%, 9.96 \%, 5.96 \%$, and $9.94 \%$ at $1,3,6$, and 22 months, respectively. Furthermore, the frequency of perforated spines at 22 months of age was just 1.67-fold higher than at 6 months and 3.68-fold higher than at 1 month in the A53T-BAC-SNCA mice. There was hardly any difference in the frequency of perforated spines between 3 and 22 months of age in A53T-BAC-SNCA mice. In addition, the percentage of perforated spines was approximately 2-fold larger in WT mice than in A53T-BAC- 

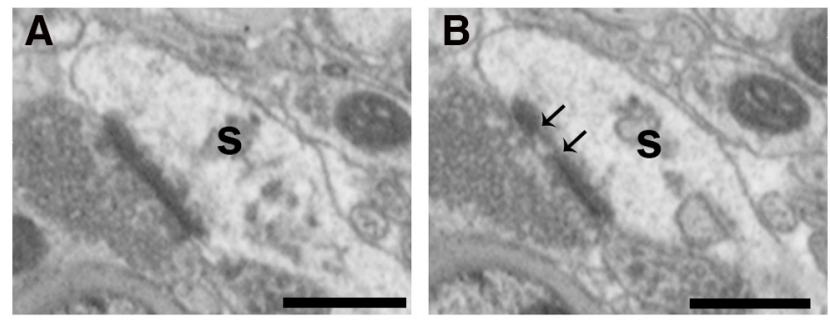
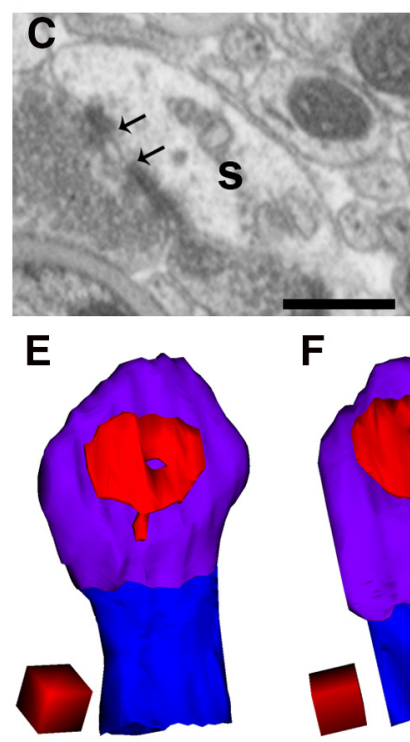

$\mathbf{F}$

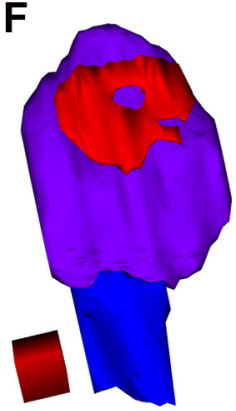

G

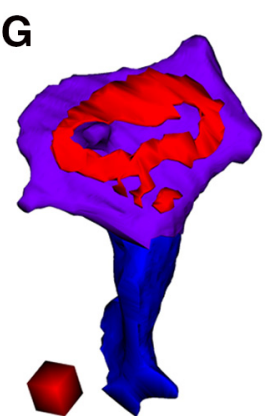

Figure 4. Examples of perforated spines in WT mice at 22 months of age. $\boldsymbol{A}-\boldsymbol{D}$, Serial images of a large spine (s). Arrows in $\boldsymbol{B}, \boldsymbol{C}$ show the discontinuity of the PSD. Scale bars: $500 \mathrm{~nm}$. $\boldsymbol{E}-\boldsymbol{G}$, Representative images of a 3D reconstruction of spines showing a doughnut-shaped perforated PSD with a hole at the center. Spine heads, spine necks, and PSDs are shown in violet, blue, and red, respectively. Scale cubes: $0.25 \mu \mathrm{m}$ on each side.

SNCA mice at 22 months of age. This suggests that spine perforation increases with age in WT mice, and that an abnormality exists in either the formation, maintenance, or elimination of perforated spines in A53T-BAC-SNCA mice.

\section{The linear relationship between spine head volume and PSD area is maintained in A53T-BAC-SNCA mice}

It has been well-established that spine head volume is positively correlated with both PSD area and AMPA receptor content (Wilson et al., 1983; Matsuzaki et al., 2001). Thus, spine head volume is often considered a proxy for synaptic strength. Because the A53T-BACSNCA mouse demonstrated abnormal development and maturation of spine head volume, we investigated whether the linear relationship between head volume and PSD area was disrupted in A53T-BAC-SNCA mice. To do this, we plotted the head volume of spines against their PSD area. The plot revealed a strong and significant correlation between head volume and PSD area, both in WT (Fig. 5A,C,E,G) and A53T-BAC-SNCA (Fig. 5B,D,F,H) mice at all four ages examined. Furthermore, the slope of the regression line was not considerably different between the WT and A53T-BAC-SNCA mice. Taken together, these data demonstrate that the basic architectural relationship between spine head volume and PSD area is not altered in A53T-BAC-SNCA mice.

\section{Aggregation of phosphorylated $\alpha$-synuclein in a subset of presynaptic terminals in A53T-BAC-SNCA mice}

Last, we examined the precise localization of phosphorylated $\alpha$-synuclein in striatal dendrites and spines in A53T-BAC-SNCA mice. A previous study (Taguchi et al., 2020a) using proteinase K-treated sections reported strong immunoreactivity for phosphorylated $\alpha$-synuclein in the cortex, amygdala, and hippocampus of A53T-BACSNCA mice. Immunoreactivity in the striatum was relatively weak, but some punctate staining was observed. To further resolve the neuronal compartments that are immunoreactive for phosphorylated $\alpha$-synuclein in A53T-BACSNCA mice, we used a pre-embedding immunogold EM labeling method. TEM observation demonstrated a selective localization of immunogold particles indicating that phosphorylated $\alpha$-synuclein existed in a subset of presynaptic terminals (Fig. 6A-E). In addition, we observed a cluster of several immunogold particles in a number of instances. Furthermore, the immunoreactivity was only observed in a subset of large presynaptic terminals (Fig. 6E). No immunogold particles were observed in presynaptic terminals in sections from WT mice (data not shown).

\section{Discussion}

Dendritic spines are vulnerable to structural changes during aging and in neurologic diseases (Ferrante et al., 1991; Dickstein et al., 2013; Mostany et al., 2013; Le et al., 2014; Pereira et al., 2014; Dorostkar et al., 2015; Herms and Dorostkar, 2016; Sato and Okabe, 2019). Previous studies have mainly used light microscopy or single-section TEM to assess structural changes in PD. However, light microscopy does not have sufficient resolution to pinpoint individual spines, and TEM images of single sections provide an incomplete picture of spine morphology, thus confounding our interpretation of ultrastructure. FIB/SEM is ideally suited to examine ultrastructure because of its ability to acquire 3D images of dendrites and spines in a completely automated manner, without the time-consuming preoccupations of image distortion, alignment, and section thickness variability that occur with serial section TEM. Furthermore, because the image acquisition is automated, simultaneous comparisons of neuropil can be performed among animal models across different ages in a reliable manner, with identical imaging conditions. To the best of our knowledge, this is the first study to systematically compare structural abnormalities across various ages in an animal model of PD.

We specifically chose the striatum for our study as this brain region is associated with both the prodromal and late stages of PD. Sleep disorder is one of the major hallmarks of prodromal PD, and the previous finding of abnormal expression of sleep-related gene networks in the striatum of PD patients (Jiang et al., 2019) indicates a possible link between this brain region and the prodromal 

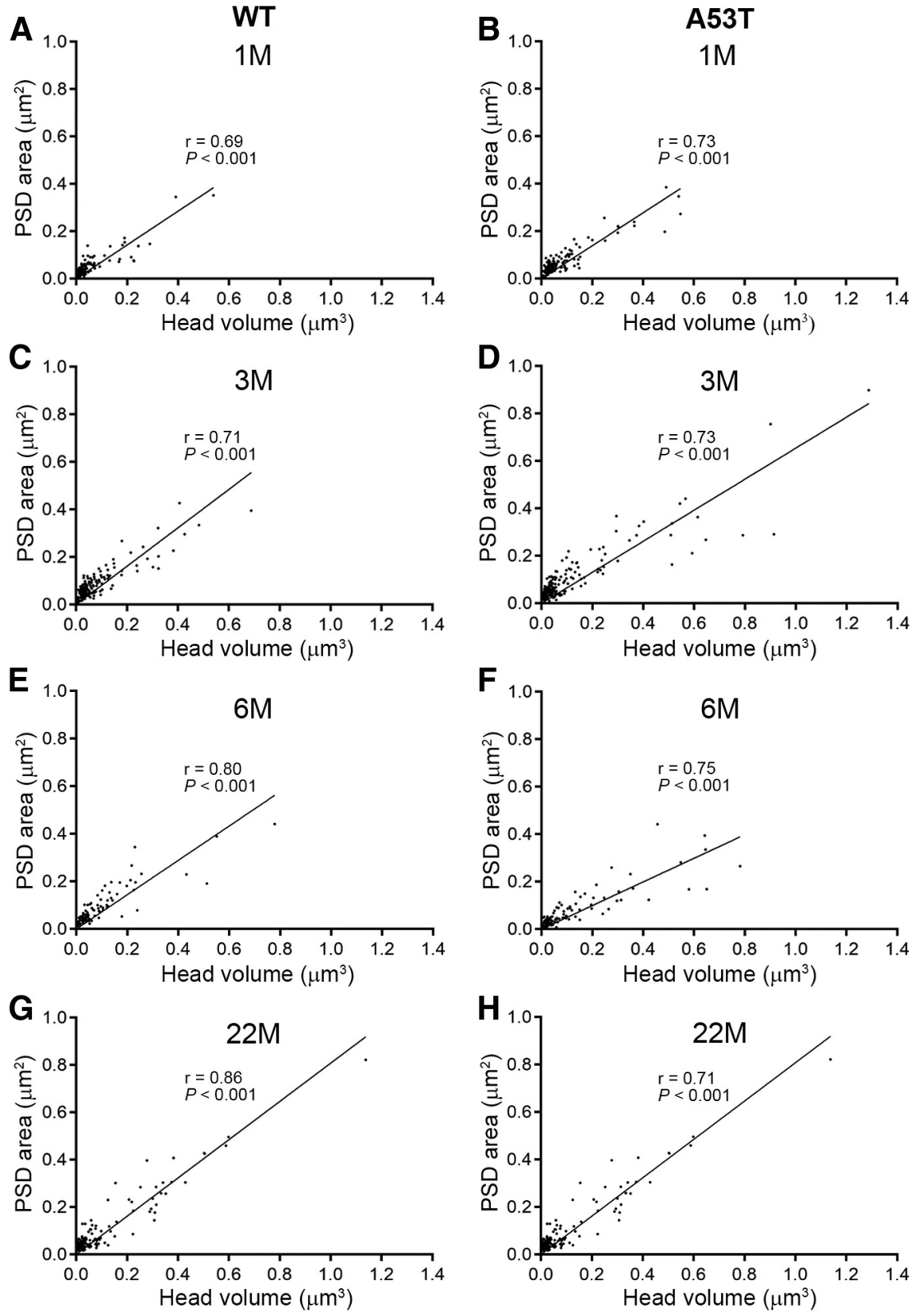

Figure 5. PSD area was correlated with spine head volume in both WT and A53T-BAC-SNCA mice. $\boldsymbol{A}-\boldsymbol{H}, \mathrm{A}$ significant, positive linear correlation exists between PSDs and spine head volumes in both WT $(\boldsymbol{A}, \boldsymbol{C}, \boldsymbol{E}, \boldsymbol{G})$ and A53T-BAC-SNCA $(\boldsymbol{B}, \boldsymbol{D}, \boldsymbol{F}, \boldsymbol{H})$ mice at all four examined ages [1 month $(\boldsymbol{A}, \boldsymbol{B}) ; 3$ months $(\boldsymbol{C}, \boldsymbol{D}) ; 6$ months $(\boldsymbol{E}, \boldsymbol{F}) ; 22$ months $(\boldsymbol{G}, \boldsymbol{H})$ ]. The correlation coefficients and the $p$ values for the test of statistical significance of correlation are denoted by $r$ and $p$, respectively, in the corresponding graphs. Correlation was examined using Spearman's rank order test.

stage of PD. Furthermore, the striatum is also known to be affected in the late phase of PD, when motor-related abnormalities become apparent. Thus, analysis of striatal neuropil can provide knowledge on the structural changes during PD both in the prodromal stage and as well as in the late phase.

An age-dependent decline in spine density was observed in both WT and A53T-BAC-SNCA mice. Studies have shown that dopamine facilitates dendritic spine formation and maintenance (Neely et al., 2007; Fasano et al., 2013; Dos Santos et al., 2017) and normal aging is associated with loss of dopamine producing cells in SNc and decrease in dopamine concentration in the striatum (Carlsson and Winblad, 1976; McGeer et al., 1977; Fearnley and Lees, 1991; Gibb and Lees, 1991). Furthermore, age-dependent decrease in the number of dopaminergic neurons in $\mathrm{SNc}$ has also been observed in A53T-BAC-SNCA mice (Taguchi et al., 2020a). Thus, it is highly likely that age-dependent decrease in spine density in both WT and A53T-BAC-SNCA mice depends on the level of dopamine in the basal ganglia. Supporting our view, the loss of dendritic spines in neurotoxin based 

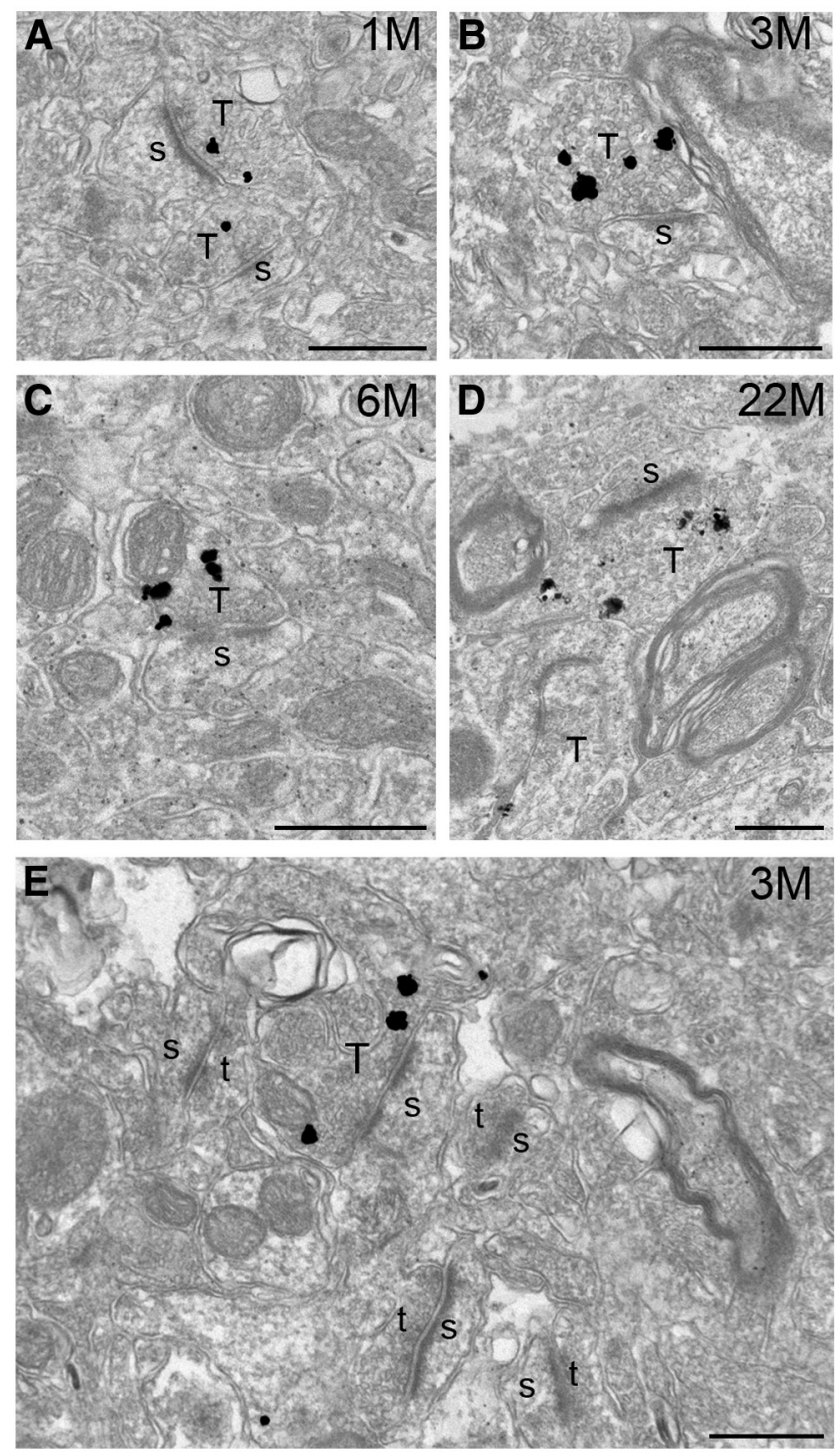

Figure 6. Localization of phosphorylated $\alpha$-synuclein in a subset of presynaptic terminals in A53T-BAC-SNCA mice. $\boldsymbol{A}-\boldsymbol{D}$, TEM images of pre-embedding immunogold-labeled samples from A53T-BAC-SNCA mice at $1(\boldsymbol{A}), 3(\boldsymbol{B}), 6(\boldsymbol{C})$, and 22 $(\boldsymbol{D})$ months. Note that the immunogold particles, indicating phosphorylated $\alpha$-synuclein, were predominantly localized to presynaptic terminals. Immunogold particles were often seen in clusters. $\boldsymbol{E}$, A low-magnification image from an A53T-BACSNCA mouse at 3 months of age demonstrates that a subset of large presynaptic terminals was immunopositive for phosphorylated $\alpha$-synuclein. s: spine; T: presynaptic terminals with immunoreactivity for phosphorylated $\alpha$-synuclein; t: presynaptic terminals lacking immunoreactivity for phosphorylated $\alpha$-synuclein. Scale bars: $500 \mathrm{~nm}$.

animal model of PD was rescued by L-dopa treatment (Fieblinger et al., 2014; Suárez et al., 2014). It is also important to note that there were significantly fewer number of dopaminergic neurons in SNc of A53T-BACSNCA mice than in WT of corresponding ages (Taguchi et al., 2020a). This can have an important consequence in the development of PD pathology. Dopamine depletion in the striatum results in an increase in striatal neuron activity (Ohye et al., 1970; Arbuthnott, 1974; Schultz and Ungerstedt, 1978), and the excessive neuronal activity as a result of reduced dopamine content in A53T-BAC-SNCA mice could underlie the manifestation of $\mathrm{PD}$.

Importantly, the decrease in spine density was accompanied by a concomitant increase in spine head size in the WT, but not mutant, mice. This result suggests that synaptic strength is conserved at all ages in WT mice. Similar to our finding, Calì et al. (2018) compared the synaptic surface area in layer 1 of the somatosensory cortex between 4- and 24-month-old mice and reported that the loss of spines at 24 months was balanced by an increase in spine head size, such that the total synaptic surface area remained constant between these two ages. A somewhat similar conclusion was also derived from previous studies of the prefrontal cortex (Duan et al., 2003; Dumitriu et al., 2010). Taken together with these earlier studies, our results support the emerging view that neurons tend to maintain an optimal excitation level and are endowed with homeostatic mechanisms to restore excitation thresholds to normal levels (Marder and Goaillard, 2006; Turrigiano, 2008). Furthermore, unlike in WT mice, the inverse relationship between spine head volume and spine density was not observed in A53T-BAC-SNCA mice, suggesting a disruption in the mechanisms that regulate homeostatic compensation of synaptic strength.

Which molecular mechanisms could play a role for the loss of age-dependent homeostatic enlargement of dendritic spines in A53T-BAC-SNCA mice? We argue that dopamine itself could be one of the major players for the bidirectional regulation of dendritic spine size. Dopamine is indispensable for induction of synaptic plasticity in striatal synapses (Reynolds et al., 2001; Gerdeman et al., 2002; Calabresi et al., 2007; Kreitzer and Malenka, 2007; Shen et al., 2008; Yagishita et al., 2014). The depleted state of dopamine in A53T-BAC-SNCA mice could result in an abnormal synaptic plasticity and misregulation of homeostatic balance in striatal synapse. In addition to the changes in dopamine levels, progressive accumulation of phosphorylated $\alpha$-synuclein in the A53T-BAC-SNCA mice could also account for the loss of homeostatic enlargement of dendritic spines. Our pre-embedding immunogold labeling experiment showed accumulation of phosphorylated $\alpha$-synuclein in the presynaptic terminals making synaptic contact with a subset of large mushroom-type spines. Because $\alpha$-synuclein deposits inhibit the vesicular release of neurotransmitters from presynaptic terminals (Nemani et al., 2010; Scott et al., 2010), spines forming synaptic contacts with $\alpha$-synuclein-positive terminals receive either sub-optimal presynaptic input or may even be completely devoid of glutamatergic signaling. Presynaptic activity is necessary for the survival of postsynaptic spines (McKinney, 2010); thus, the absence of vesicular release from the presynaptic terminal may render a subset of mushroom-type spines making synaptic contact with $\alpha$-synuclein containing terminals nonfunctional and lead to their eventual elimination. This might explain the lower frequency of mushroom-type 
spines and smaller average head volume in the striatal spines of A53T-BAC-SNCA mice compared with WT mice. In turn, owing to the loss of a subset of mushroomtype spines, numerous small size spines may form as a homeostatic response to compensate for the reduction in total synaptic strength of dendrites in A53T-BAC-SNCA mice and result in higher spine density in A53T-BACSNCA mice than in the WT. The altered homeostatic regulation of dendritic spine size in A53T-BAC-SNCA mice is likely to cause a shift in the excitation-inhibition balance in the striatal network.

The lower frequency of mushroom-type spines in A53TBAC-SNCA mice was also corroborated by a 2-fold decrease in the number of perforated spines in this PD mouse model. Thin-type spines primarily harbor macular, simple PSDs, while large, mushroom-type spines harbor perforated PSDs. Although the function of spine perforation remains unclear, studies have reported a correlative link between the abundance of perforated spines and cognitive ability in animals (Geinisman et al.,1986; Hara et al., 2012). Large, mushroom-type, perforated spines are believed to be the structural substrate for the storage of stable, non-malleable forms of memory; thus, the lower abundance of perforated spines in A53T-BAC-SNCA mice suggest a deficit in their long-term memory formation and storage.

Motor symptoms associated with PD in humans' manifests later in life, typically after 50 years of age. However, in the present study, synaptic abnormalities in mice were already apparent at 1 month of age. It is crucial to mention that A53T-BAC-SNCA mice that we have used in this study recapitulate the symptoms and pathologies of prodromal PD (Taguchi et al., 2020a). Various non-motor related neurologic abnormalities associated with prodromal PD are already evident as early as two to three months of age in the mouse models that mimics prodromal PD (Paumier et al., 2013; Taguchi et al., 2020b), but the gross motor dysfunctions appear much later in life coinciding with the significant degeneration of dopaminergic neurons (Taguchi et al., 2020b). In A53T-BAC-SNCA mice, a significant decrease in the number of tyrosine hydroxylase (TH)-positive dopaminergic cells in the substantia nigra is observed at 9 and 18 months but not at 3 months (Taguchi et al., 2020a). This observation supports the prevailing idea that the onset of synaptic abnormalities and prodromal symptoms of PD precede the degeneration of dopaminergic cells and consequent manifestation of motor symptoms (Guidetti et al., 2001; Klapstein et al., 2001; Taguchi et al., 2020b). In future, it will be important to explore if distinct subcellular mechanisms are involved in the pathologies of the early prodromal stage and advanced, clinical stage of PD, and whether the former depends on the structural changes that occur at the synaptic level and the latter depends on the significant degeneration of dopaminergic cells in the basal ganglia.

Finally, it is noteworthy to mention that the structural observation of synapses at only one age provides an incomplete and misleading picture of the structural abnormalities during PD. Our study demonstrates that distinct structural changes occur at different ages in PD. We believe that the morphologies that we have characterized here are fundamental to the regulation of synaptic function and will serve as a basis for the physiological interpretation of synaptic abnormalities in PD.

\section{References}

Appel-Cresswell S, Vilarino-Guell C, Encarnacion M, Sherman H, Yu I, Shah B, Weir D, Thompson C, Szu-Tu C, Trinh J, Aasly JO, Rajput A, Rajput AH, Jon Stoessl A, Farrer MJ (2013) Alpha-synuclein p.H50Q, a novel pathogenic mutation for Parkinson's disease. Mov Disord 28:811-813.

Araya R, Jiang J, Eisenthal KB, Yuste R (2006) The spine neck filters membrane potentials. Proc Natl Acad Sci USA 103:17961-17966.

Arbuthnott GW (1974) Spontaneous activity of single units in the striatum after unilateral destruction of the dopamine input. $J$ Physiol 239:121-122.

Calabresi P, Picconi B, Tozzi A, Di Filippo M (2007) Dopamine-mediated regulation of corticostriatal synaptic plasticity. Trends Neurosci 30:211-219.

Calì C, Wawrzyniak M, Becker C, Maco B, Cantoni M, Jorstad A, Nigro B, Grillo F, De Paola V, Fua P, Knott GW (2018) The effects of aging on neuropil structure in mouse somatosensory cortex-A 3D electron microscopy analysis of layer 1. PLoS One 13: e0198131.

Carlsson A, Winblad B (1976) Influence of age and time interval between death and autopsy on dopamine and 3-methoxytyramine levels in human basal ganglia. J Neural Transm 38:271-276.

Delic V, Chandra S, Abdelmotilib H, Maltbie T, Wang S, Kem D, Scott HJ, Underwood RN, Liu Z, Volpicelli-Daley LA, West AB (2018) Sensitivity and specificity of phospho-Ser129 $\alpha$-synuclein monoclonal antibodies. J Comp Neurol 526:1978-1990.

Dickstein DL, Weaver CM, Luebke JI, Hof PR (2013) Dendritic spine changes associated with normal aging. Neuroscience 251:21-32.

Dorostkar MM, Zou C, Blazquez-Llorca L, Herms J (2015) Analyzing dendritic spine pathology in Alzheimer's disease: problems and opportunities. Acta Neuropathol 130:1-19.

Dos Santos M, Salery M, Forget B, Garcia Perez MA, Betuing S, Boudier T, Vanhoutte P, Caboche J, Heck N (2017) Rapid synaptogenesis in the nucleus accumbens is induced by a single cocaine administration and stabilized by mitogen-activated protein kinase interacting kinase-1 activity. Biol Psychiatry 82:806-818.

Duan H, Wearne SL, Rocher AB, Macedo A, Morrison JH, Hof PR (2003) Age-related dendritic and spine changes in corticocortically projecting neurons in macaque monkeys. Cereb Cortex 13:950961.

Dumitriu D, Hao J, Hara Y, Kaufmann J, Janssen WG, Lou W, Rapp PR, Morrison JH (2010) Selective changes in thin spine density and morphology in monkey prefrontal cortex correlate with agingrelated cognitive impairment. J Neurosci 30:7507-7515.

Erro R, Stamelou M (2017) The motor syndrome of Parkinson's disease. Int Rev Neurobiol 132:25-32.

Fasano C, Bourque MJ, Lapointe G, Leo D, Thibault D, Haber M, Kortleven C, Desgroseillers L, Murai KK, Trudeau LÉ (2013) Dopamine facilitates dendritic spine formation by cultured striatal medium spiny neurons through both D1 and D2 dopamine receptors. Neuropharmacology 67:432-443.

Fearnley JM, Lees AJ (1991) Ageing and Parkinson's disease: substantia nigra regional selectivity. Brain 114:2283-2301.

Ferrante RJ, Kowall NW, Richardson EP (1991) Proliferative and degenerative changes in striatal spiny neurons in Huntington's disease: a combined study using the section-Golgi method and calbindin D28k immunocytochemistry. J Neurosci 11:3877-3887.

Fiala JC (2005) Reconstruct: a free editor for serial section microscopy. J Microsc 218:52-61.

Fieblinger T, Graves SM, Sebel LE, Alcacer C, Plotkin JL, Gertler TS, Chan CS, Heiman M, Greengard P, Cenci MA, Surmeier DJ (2014) Cell type-specific plasticity of striatal projection neurons in parkinsonism and L-DOPA-induced dyskinesia. Nat Commun 5:5316. 
Funamizu Y, Nishijima H, Ueno T, Ueno S, Mizukami H, Yagihashi S, Tomiyama M (2017) Morphological dendritic spine changes of medium spiny neurons in the nucleus accumbens in 6-hydroxydopamine-lesioned rats treated with levodopa. Neurosci Res 121:4953.

Gagnon D, Petryszyn S, Sanchez MG, Bories C, Beaulieu JM, De Koninck Y, Parent A, Parent M (2017) Striatal neurons expressing D1 and D2 receptors are morphologically distinct and differently affected by dopamine denervation in mice. Sci Rep 7:41432.

Garcia BG, Neely MD, Deutch AY (2010) Cortical regulation of striatal medium spiny neuron dendritic remodeling in parkinsonism: modulation of glutamate release reverses dopamine depletion-induced dendritic spine loss. Cereb Cortex 20:2423-2432.

Gasser T (2009) Molecular pathogenesis of Parkinson disease: insights from genetic studies. Expert Rev Mol Med 11:e22.

Geinisman Y, de Toledo-Morrell L, Morrell F (1986) Loss of perforated synapses in the dentate gyrus: morphological substrate of memory deficit in aged rats. Proc Natl Acad Sci USA 83:30273031.

Gerdeman GL, Ronesi J, Lovinger DM (2002) Postsynaptic endocannabinoid release is critical to long-term depression in the striatum. Nat Neurosci 5:446-451.

Gerfen CR (1988) Synaptic organization of the striatum. J Electron Microsc Tech 10:265-281.

Gibb WR, Lees AJ (1991) Anatomy, pigmentation, ventral and dorsal subpopulations of the substantia nigra, and differential cell death in Parkinson's disease. J Neurol Neurosurg Psychiatry 54:388396.

Guidetti P, Charles V, Chen EY, Reddy PH, Kordower JH, Whetsell WO Jr, Schwarcz R, Tagle DA (2001) Early degenerative changes in transgenic mice expressing mutant huntingtin involve dendritic abnormalities but no impairment of mitochondrial energy production. Exp Neurol 169:340-350.

Hara Y, Park CS, Janssen WG, Roberts MT, Morrison JH, Rapp PR (2012) Synaptic correlates of memory and menopause in the hippocampal dentate gyrus in rhesus monkeys. Neurobiol Aging 33:421.e17-e28.

Herms J, Dorostkar MM (2016) Dendritic spine pathology in neurodegenerative diseases. Annu Rev Pathol 11:221-250.

Jankovic J (2008) Parkinson's disease: clinical features and diagnosis. J Neurol Neurosurg Psychiatry 79:368-376.

Jiang P, Scarpa JR, Gao VD, Vitaterna MH, Kasarskis A, Turek FW (2019) Parkinson's disease is associated with dysregulations of a dopamine-modulated gene network relevant to sleep and affective neurobehaviors in the striatum. Sci Rep 9:4808.

Kiely AP, Asi YT, Kara E, Limousin P, Ling H, Lewis P, Proukakis C, Quinn N, Lees AJ, Hardy J, Revesz T, Houlden H, Holton JL (2013) $\alpha$-Synucleinopathy associated with G51D SNCA mutation: a link between Parkinson's disease and multiple system atrophy? Acta Neuropathol 125:753-769.

Klapstein GJ, Fisher RS, Zanjani H, Cepeda C, Jokel ES, Chesselet MF, Levine MS (2001) Electrophysiological and morphological changes in striatal spiny neurons in R6/2 Huntington's disease transgenic mice. J Neurophysiol 86:2667-2677.

Klein C, Westenberger A (2012) Genetics of Parkinson's disease. Cold Spring Harb Perspect Med 2:a008888.

Kreitzer AC, Malenka RC (2007) Endocannabinoid-mediated rescue of striatal LTD and motor deficits in Parkinson's disease models. Nature 445:643-647.

Krüger R, Kuhn W, Müller T, Woitalla D, Graeber M, Kösel S, Przuntek H, Epplen JT, Schöls L, Riess O (1998) Ala30Pro mutation in the gene encoding $\alpha$-synuclein in Parkinson's disease. Nat Genet 18:106-108.

Kuwajima M, Spacek J, Harris KM (2013) Beyond counts and shapes: studying pathology of dendritic spines in the context of the surrounding neuropil through serial section electron microscopy. Neuroscience 251:75-89.

Le Y, Liu S, Peng M, Tan C, Liao Q, Duan K, Ouyang W, Tong J (2014) Aging differentially affects the loss of neuronal dendritic spine, neuroinflammation and memory impairment at rats after surgery. PLoS One 9:e106837.

Lees AJ, Hardy J, Revesz T (2009) Parkinson's disease. Lancet 373:2055-2066.

Marder E, Goaillard JM (2006) Variability, compensation and homeostasis in neuron and network function. Nat Rev Neurosci 7:563574.

Matikainen-Ankney BA, Kezunovic N, Mesias RE, Tian Y, Williams FM, Huntley GW, Benson DL (2016) Altered development of synapse structure and function in striatum caused by Parkinson's disease-linked LRRK2-G2019S mutation. J Neurosci 36:7128-7141.

Matsuzaki M, Ellis-Davies GCR, Nemoto T, Miyashita Y, lino M, Kasai H (2001) Dendritic spine geometry is critical for AMPA receptor expression in hippocampal CA1 pyramidal neurons. Nat Neurosci 4:1086-1092.

McGeer PL, McGeer EG, Suzuki JS (1977) Aging and extrapyramidal function. Arch Neurol 34:33-35.

McKinney RA (2010) Excitatory amino acid involvement in dendritic spine formation, maintenance and remodelling. J Physiol 588:107116.

McNeill TH, Brown SA, Rafols JA, Shoulson I (1988) Atrophy of medium spiny I striatal dendrites in advanced Parkinson's disease. Brain Res 455:148-152.

Mostany R, Anstey JE, Crump KL, Maco B, Knott G, Portera-Cailliau C (2013) Altered synaptic dynamics during normal brain aging. J Neurosci 33:4094-4104.

Naskar A, Manivasagam T, Chakraborty J, Singh R, Thomas B, Dhanasekaran M, Mohanakumar KP (2013) Melatonin synergizes with low doses of L-DOPA to improve dendritic spine density in the mouse striatum in experimental Parkinsonism. J Pineal Res 55:304-312.

Neely MD, Schmidt DE, Deutch AY (2007) Cortical regulation of dopamine depletion-induced dendritic spine loss in striatal medium spiny neurons. Neuroscience 149:457-464.

Nemani VM, Lu W, Berge V, Nakamura K, Onoa B, Lee MK, Chaudhry FA, Nicoll RA, Edwards RH (2010) Increased expression of alpha-synuclein reduces neurotransmitter release by inhibiting synaptic vesicle reclustering after endocytosis. Neuron 65:66-79.

Ohye C, Bouchard R, Larochelle L, Bédard P, Boucher R, Raphy B, Poirier LJ (1970) Effect of dorsal rhizotomy on postural tremor in the monkey. Exp Brain Res 10:140-150.

Parajuli LK, Tanaka S, Okabe S (2017) Insights into age-old questions of new dendritic spines: from form to function. Brain Res Bull 129:3-11.

Pasanen P, Myllykangas L, Siitonen M, Raunio A, Kaakkola S, Lyytinen J, Tienari PJ, Pöyhönen M, Paetau A (2014) Novel $\alpha$-synuclein mutation A53E associated with atypical multiple system atrophy and Parkinson's disease-type pathology. Neurobiol Aging 35:2180.e1-e5.

Paumier KL, Sukoff Rizzo SJ, Berger Z, Chen Y, Gonzales C, Kaftan E, Li L, Lotarski S, Monaghan M, Shen W, Stolyar P, Vasilyev D, Zaleska M, Hirst WD, Dunlop J (2013) Behavioral characterization of A53T mice reveals early and late stage deficits related to Parkinson's disease. PLoS One 8:e70274.

Penzes P, Cahill ME, Jones KA, VanLeeuwen JE, Woolfrey KM (2011) Dendritic spine pathology in neuropsychiatric disorders. Nat Neurosci 14:285-293.

Pereira AC, Lambert HK, Grossman YS, Dumitriu D, Waldman R, Jannetty SK, Calakos K, Janssen WG, McEwen BS, Morrison JH (2014) Glutamatergic regulation prevents hippocampal-dependent age-related cognitive decline through dendritic spine clustering. Proc Natl Acad Sci USA 111:18733-18738.

Polymeropoulos MH, Lavedan C, Leroy E, Ide SE, Dehejia A, Dutra A, Pike B, Root H, Rubenstein J, Boyer R, Stenroos ES, Chandrasekharappa S, Athanassiadou A, Papapetropoulos T, Johnson WG, Lazzarini AM, Duvoisin RC, Di lorio G, Golbe LI, Nussbaum RL (1997) Mutation in the $\alpha$-synuclein gene identified in families with Parkinson's disease. Science 276:2045-2047.

Reynolds JNJ, Hyland BI, Wickens JR (2001) A cellular mechanism of reward-related learning. Nature 413:67-70. 
Riederer P, Berg D, Casadei N, Cheng F, Classen J, Dresel C, Jost W, Krüger R, Müller T, Reichmann H, Rieß O, Storch A, Strobel S, van Eimeren T, Völker HU, Winkler J, Winklhofer KF, Wüllner U, Zunke F, Monoranu CM (2019) $\alpha$-Synuclein in Parkinson's disease: causal or bystander? J Neural Transm (Vienna) 126:815-840.

Sato Y, Okabe S (2019) Nano-scale analysis of synapse morphology in an autism mouse model with 15q11-13 copy number variation using focused ion beam milling and scanning electron microscopy. Microscopy (Oxf) 68:122-132.

Schindelin J, Arganda-Carreras I, Frise E, Kaynig V, Longair M, Pietzsch T, Preibisch S, Rueden C, Saalfeld S, Schmid B, Tinevez JY, White DJ, Hartenstein V, Eliceiri K, Tomancak P, Cardona A (2012) Fiji: an open-source platform for biological-image analysis. Nat Methods 9:676-682.

Schultz W, Ungerstedt U (1978) Striatal cell supersensitivity to apomorphine in dopamine-lesioned rats correlated to behaviour. Neuropharmacology 17:349-353.

Scott DA, Tabarean I, Tang Y, Cartier A, Masliah E, Roy S (2010) A pathologic cascade leading to synaptic dysfunction in alpha-synuclein-induced neurodegeneration. J Neurosci 30:8083-8095.

Shen W, Flajolet M, Greengard P, Surmeier DJ (2008) Dichotomous dopaminergic control of striatal synaptic plasticity. Science 321:848-851.

Simon DK, Tanner CM, Brundin P (2020) Parkinson disease epidemiology, pathology, genetics, and pathophysiology. Clin Geriatr Med 36:1-12.

Solis O, Limón DI, Flores-Hernández J, Flores G (2007) Alterations in dendritic morphology of the prefrontal cortical and striatum neurons in the unilateral 6-OHDA-rat model of Parkinson's disease. Synapse 61:450-458.

Spillantini MG, Crowther RA, Jakes R, Hasegawa M, Goedert M (1998) $\alpha$-Synuclein in filamentous inclusions of Lewy bodies from Parkinson's disease and dementia with Lewy bodies. Proc Natl Acad Sci USA 95:6469-6473.

Stephens B, Mueller AJ, Shering AF, Hood SH, Taggart P, Arbuthnott GW, Bell JE, Kilford L, Kingsbury AE, Daniel SE, Ingham CA (2005) Evidence of a breakdown of corticostriatal connections in Parkinson's disease. Neuroscience 132:741-754.

Suárez LM, Solís O, Caramés JM, Taravini IR, Solís JM, Murer MG, Moratalla R (2014) L-DOPA treatment selectively restores spine density in dopamine receptor D2-expressing projection neurons in dyskinetic mice. Biol Psychiatry 75:711-722.
Taguchi T, Ikuno M, Hondo M, Parajuli LK, Taguchi K, Ueda J, Sawamura M, Okuda S, Nakanishi E, Hara J, Uemura N, Hatanaka Y, Ayaki T, Matsuzawa S, Tanaka M, El-Agnaf OMA, Koike M, Yanagisawa M, Uemura MT, Yamakado H, et al. (2020a) $\alpha$-Synuclein BAC transgenic mice exhibit RBD-like behaviour and hyposmia: a prodromal Parkinson's disease model. Brain 143: 249-265.

Taguchi T, Ikuno M, Yamakado H, Takahashi R (2020b) Animal model for prodromal Parkinson's disease. Int J Mol Sci 21:1961.

Tønnesen J, Nägerl UV (2016) Dendritic spines as tunable regulators of synaptic signals. Front Psychiatry 7:101.

Tsukita K, Sakamaki-Tsukita H, Tanaka K, Suenaga T, Takahashi R (2019) Value of in vivo $\alpha$-synuclein deposits in Parkinson's disease: a systematic review and meta-analysis. Mov Disord 34:14521463.

Turrigiano GG (2008) The self-tuning neuron: synaptic scaling of excitatory synapses. Cell 135:422-435.

Villalba RM, Smith Y (2013) Differential striatal spine pathology in Parkinson's disease and cocaine addiction: a key role of dopamine? Neuroscience 251:2-20.

Villalba RM, Smith Y (2018) Loss and remodeling of striatal dendritic spines in Parkinson's disease: from homeostasis to maladaptive plasticity? J Neural Transm (Vienna) 125:431-447.

Villalba RM, Lee H, Smith Y (2009) Dopaminergic denervation and spine loss in the striatum of MPTP-treated monkeys. Exp Neurol 215:220-227.

Wilson CJ, Groves PM, Kitai ST, Linder JC (1983) Three-dimensional structure of dendritic spines in the rat neostriatum. $J$ Neurosci 3:383-388.

Yagishita S, Hayashi-Takagi A, Ellis-Davies GCR, Urakubo H, Ishii S, Kasai $H$ (2014) A critical time window for dopamine actions on the structural plasticity of dendritic spines. Science 345:1616-1620.

Zaja-Milatovic S, Milatovic D, Schantz AM, Zhang J, Montine KS, Samii A, Deutch AY, Montine TJ (2005) Dendritic degeneration in neostriatal medium spiny neurons in Parkinson disease. Neurology 64:545-547.

Zarranz JJ, Alegre J, Gómez-Esteban JC, Lezcano E, Ros R, Ampuero I, Vidal L, Hoenicka J, Rodriguez O, Atarés B, Llorens V, Gomez Tortosa E, del Ser T, Muñoz DG, de Yebenes JG (2004) The new mutation, E46K, of $\alpha$-synuclein causes Parkinson and Lewy body dementia. Ann Neurol 55:164-173. 